\title{
Exploring PBL Online Teaching to Enhance Students' Meta-Learning Skills
}

\author{
Yajie Chen ${ }^{1, *, \dagger}$, Yilin $\operatorname{Liu}^{2, *, \dagger}$ \\ ${ }^{1}$ School of Translation Studies, Xi'an International Studies University, 710049, Xi'an, Shaanxi Province, China \\ ${ }^{2}$ School of Translation Studies, Xi'an International Studies University, 7100490, Xi'an, Shaanxi Province, China \\ ${ }^{*}$ Corresponding author. Email: ${ }^{1} 107242018000565 @$ stu.xisu.edu.cn, ${ }^{2} 107242019001765 @$ stu.xisu.edu.cn \\ Those authors contributed equally.
}

\begin{abstract}
This paper reviews mainly on PBL online teaching model and some online teaching practice to explore the necessity that students are supposed to acquire. The paper first introduces the conception of meta-learning skills which can be highly described as learning skills in the process of students' learning. Then, background and objectives on PBL are given in the main body to bring an initial comprehension of PBL learning. The destination of cultivating students' capacity is to facilitate them to tackle real-life scenarios. In addition, the paper takes the case of University of Hong Kong and Wuhan Polytechnic as examples of online teaching to analyze how to carry out the practice of online teaching based on the teaching mode of Project-Based Learning (PBL), and then demonstrates advantages concerning independent ability, communication and collaboration ability and reflection competences, and then summarize this online PBL teaching mode.
\end{abstract}

Keywords: Project-based learning, Online teaching, Meta-learning skills.

\section{INTRODUCTION}

COVID-19 has rearranged the learning mode of students around the world. As information technology and education continue to merge, most schools with internet access are switching to PBL online education. The associated teaching ideas, teaching space, and teaching techniques must also be updated and changed to match the real-world demands of learners [1]. As we see more and more students adapting to the new learning style, we need to consider what benefits students will acquire in PBL online education -ample knowledge, convenient communication environment, and more importantly, learning skills. According to the University of Texas at El Paso (UTEP), online learning can enhance students' transferable skills, such as learner autonomy and communication skills. Charles Fadel, founder of the Center for Curriculum Redesign (CCR) called them "meta-learning skills", which are the highly desirable skills of "learning how to learn".

\section{BACKGROUND AND OBJECTIVES ON PBL}

While online learning is an increasing essential element of education, many countries are using it as a powerful tool for human resource development [2][3]. However, it is difficult for professors to assist students in concentrating and participating in an online course in a circumstance with Internet appeal, with its plethora of shopping websites, free online games, and social networking websites [4]. Teachers are striving to develop suitable online teaching techniques and integrate them with online technology to increase students' learning motivation and interest, as well as to preserve students' concentration [4]. Many online learning instructors use an innovative teaching technique called Project-Based Learning (PBL) and have studied its impact in online learning settings [5].

PBL was first introduced at McMaster University in the 1960s, and soon adopted in the North American and Europe in the subsequent decades, particularly in medical education as a course design and a pedagogical method [6][7]. Underpinned by the Constructivist approach, $\mathrm{PBL}$ is one of the approaches that might be used in online learning settings [8]. PBL is a studentcentered method of learning that focuses on understanding and tackling real-life scenarios that are frequently not easy [9][10]. With its emphasis on selfdirected learning, communication and collaborative 
learning and reflecting, PBL offers a learning environment in which students identify issues, form hypotheses, acquire and analyze data, and generate solutions [11]. Small group discussion is an integral component of any PBL curriculum. Small group activity naturally develops awareness and comprehension of individual diversity, as well as oral communication and teamwork abilities [12]. According to Hmelo-Silver and Eberbach, PBL should assist students in developing the following skills: independent learning skills; communication and collaboration skills; and reflecting skills on their own [13].

The concept of "Project", as a methodology was first proposed by William H. Kilpatrick in 1918. In the 1960s, the American educator John Dewey put forward the concept again. Since the 1970s, Project based teaching has been applied to vocational or professional teaching practice in Europe and America. Entering the 21 st century, PBL has been promoted and widely used in teaching and learning practice, becoming a highly respected teaching method. Different from the traditional teaching and learning method, PBL emphasizes that project is as the main point, teachers are as facilitators, and students are as the main parts. This method changes the passive teaching mode into the teaching mode of students' active involvement. This new teaching mode can stimulate students' active participation, independent collaboration and the spirit of exploration and innovation. In the specific practice of project-based teaching method, teachers design various projects to let students complete independently or in groups, guide students to discover new knowledge and master new content in practice, so as to achieve the purpose of cultivating cooperative ability and solving practical problems.

\section{CASE ANALYSIS ON PBL ONLINE COURSES DESIGN}

\subsection{Online PBL Case at University of Hong $\operatorname{Kong}(\mathrm{HKU})$}

The Division of Speech and Hearing Sciences of the University of Hong Kong (HKU) has established a complete PBL curriculum since 1997. Instead of sitting through large-group lectures, students are divided into small groups to dedicate on a series of problem cases centered on various topics with the instruction of facilitators. Group collaborations comprising students' illuminating concepts and issues in each subject for further research, constructing learning directions after relevant readings and thinking, and ultimately generating hypotheses regarding the nature of the underlying limitations. Facilitators then guide students in their learning process by providing periodical feedbacks and encouraging them to think critically. While PBL is implementing with positive outcomes, it is still faced with time and venue constrains [14]. Small groups generally participating in face-to-face interactions, a fundamental PBL characteristic, imposes tight space needs, especially when group conversations are conducted synchronously. Consequently, timetabling becomes more challenging, especially for those who have part-time work or in an internship outside campus, which makes it intricated for them to participate in PBL on campus. Online PBL learning thus becoming a prevalent mode of instruction, with many degree courses and continuing education programs embracing it.

\subsubsection{Method}

The study included two groups of third-year undergraduate students from the Division of Speech and Hearing Sciences at the University of Hong Kong: online PBL groups and traditional PBL groups. All third-year students are placed into five PBL groups of eight students each. Each PBL group is given a group leader as well as a PBL facilitator. During each PBL block, all students meet twice a week for three hours (usually on Monday and Thursday). On Mondays, a fresh problem case is assigned to the students. After studying the problem case for a while, the students create a list of learning difficulties connected to the problem case as a group. They will meet on Thursday to conduct necessary discussions under the guidance of PBL facilitators.

The outcomes of online PBL tutorials were evaluated via two instruments:

(1) a self-reported questionnaire reflecting students' experience toward online PBL;

(2) a quantitative analysis of online PBL students' academic performance [14].

The first instrument provides qualitative, selfreflecting feedback of $\mathrm{PBL}$ online experience, the second gives a quantitative data concerned with their academic performance including examination, writing tasks and evaluation during their tutorials.

\subsubsection{Results}

Questionnaire from the students suggests that all students are satisfied with the online platform and are willing to accept PBL online tutorial. Among eight students, six believes online PBL facilitate their study because it saves their time. Five students note that they can exchange their idea more efficient so that their interest is enhanced.

According to the survey, online PBL appears to be popular than traditional PBL learning. The most significant advantage of using online PBL is the reduction in travel time to and from the university 
campus, which can promote students to fully utilize their time as much as possible.

\subsection{Online PBL Case at Wuhan Polytechnic}

This case is based on an experiment of PBL teaching mode lasting two semesters. Researchers focus on curriculum teaching practice and the practical application of the theories.

\subsubsection{Teaching Object and the Selection of Teaching Materials}

The study focuses on the freshmen of Wuhan Polytechnic. And the textbook is Interactive Vocational English [15].

\subsubsection{Teaching Design Based on PBL Teaching Mode}

A teaching unit is divided into three sections: introduction project, main project and outreach project. And several small projects are designed for each section. At the commencement of the semester, all freshmen are randomly divided into six groups of five. Each PBL group contains a nominated leader. Each team is responsible for a unit project.

Before class, assignments and project requirements are provided to students in the group chat of QQ (a chatting software in China). Students are expected to prepare for materials in advance accordingly. In class, students meet and discuss relevant issues under the guidance of the teacher. Then they complete each assignment individually or collaboratively based on different project requirements, followed by submission to teachers for modification. Finally, students are encouraged to present their achievements with teachers and other groups' subsequent evaluation on the performance. After class, students raise questions based on this teaching unit in the QQ group, and the teacher will provide feedback for them in the next live class.

\subsubsection{The Implementation of Teaching Design}

Before class, students have completed the learning of text words and key sentences by themselves. The main goal of unit teaching is to help students finish the reading comprehension and develop the topic of the unit. The teaching objective of Project 3 is to guide students to use scanning and skimming to read texts and solve the problem of the comprehension. The teaching objective of Project 4 is to guide students how to tackle real-life scenarios in the future. The specific arrangements are as follows:

Before class, every group is required to read relevant files and complete the 5 to 10 information matching questions in advance. Then they submit their answers to the teacher for check and modification. During class, one student is selected from each group to explain their answers with PowerPoint, followed by the instruction from the teacher to facilitate students to assimilate the text information. There are interactive discussions between different groups and teachers. The responsibility for a teacher is to guide and organize peer evaluation, to give analysis and summary, and to promote the effect of teaching.

\subsubsection{The Analysis of This Case}

During the implementation of project teaching, the process is more important than the result, because the process of participation is the process of creation and practice. "The first task of foreign language teaching is to learn and not to teach." The role of teachers is no longer to convey knowledge, but to guide students. In addition, online teaching cannot carry out effective realtime interaction and pay attention to whether each student's learning is synchronized with the teacher's teaching compared with offline teaching. PBL teaching can effectively supervise the students' learning process in stages, motivate students to study independently, help students to advance quickly on the road of independent research, and improve their skills related to the teaching contents. At the same time, teachers can enhance their own quality and improve their teaching levels in the process of designing projects, guiding, supervising and helping students to complete project tasks. Therefore, PBL teaching mode advocates teachers and students to complete the project together and make progress together, which is a win-win on both sides.

\section{THE ADVANTAGES OF ONLINE PBL TEACHING MODE}

\subsection{Independence Learning}

Online education increases students' learning independence. First, online courses offer students greater control over their own learning by enabling them to work at their own pace. Different from the busy life of four classes a day in offline education, online education allows students to plan for two classes a day to give themselves more time to digest knowledge and preview new lessons. Online teaching can be regarded as a kind of information exchange activity based on the background of the network. Students are always in the huge knowledge pool of the Network and can quickly obtain a variety of learning resources. In the process of resource comparison and brainstorming, students learn from each other's strengths and weaknesses, which promotes students' independent thinking and makes them no longer superstitious about teachers to engage in critical learning. 
Second, students can study anytime, anywhere. Online learning gives them a chance to choose a suitable study environment like a comfortable study, quiet library or a beautiful coffee shop. Some students may prefer to study Advanced Mathematics courses on MOOC at 7:30 a.m. for sharpest concentration. The convenience of online teaching creates a relaxed and pleasant learning atmosphere, which is more conducive to students' releasing their nature, giving play to their intelligence and wisdom, and communicating, inspiring and cooperating with each other in learning.

Also, teachers and schools no longer use the arranged learning activities to restrain students in online education. Students donot have to attend meaningless lectures on advertising and student union conferences so that there will be more time and energy for them to learn Python or Shakespeare.

It helps teach students according to their aptitude. Students have different personalities and abilities, which determines the diversity of students' learning motivation, behavior and pressure. However, traditional classes require students to concentrate and follow the teacher's plan of teaching, which leads to boredom and rebellious psychology among some students. In the context of network, students can adopt different learning methods according to their own characteristics.

\subsection{Communications and Collaborations}

Online education improves students' academic communication and collaboration abilities. Convenient as e-mail, Tencent Meeting and WeChat offer opportunities for more personal and efficient interaction. You can simply pick up a WeChat call with your teacher to figure out what needs improvement in your graduation thesis without bothering to take a shuttle run between Teaching Building A and Z. All you have to do is to find a room with strong Wi-Fi. In addition, introverted students who dare not ask questions may show their true ideas on the internet. When it comes to participating in discussions and focusing on personal activities, they are usually good listeners and can better express ideas by writing rather than verbally. Thus, those students don't have to meet in face-to-face conversations, which may arouse their nervous feeling. Furthermore, online learning still provides an ideal platform for students to engage in group discussions with easier management and faster completion. Once an assignment is confirmed, a collaborative group can take a Tencent Meeting to brainstorm and share viable decisions. After the feedback session, a Word or PowerPoint document can also be completed together with the Online Cooperative Office System.

\subsection{Learning Reflection}

Students' learning reflection is fully stimulated in online education. Online class videos and learning materials can be viewed repeatedly, which provides convenience for students to reflect and review. That is to say, before the mid-term exam, students can still rewind, and re-watch the history lesson they took at the beginning of school. Down-loadable PDF documents are also available for review. Besides, frequent assessment in online courses enables students to find their own problems better. If students take online classes on the Superstar (an online education application) platform, they will be tested every ten minutes. The platform will give an evaluation after the completion of the answer, and students can reflect on their own questions accordingly. Last but not least, it is easy for students to find relevant information on the Internet to fill in the knowledge gaps. Students can take professional law courses on Bilibili (a streaming video platform like Netflix) and supplement their English knowledge on the official website of Cambridge University. Even on Weibo, they could readily find a complete set of advanced mathematics notes shared by other people.

\section{CONCLUSION}

The paper begins by introducing the concept of meta-learning skills, which can be broadly defined as the ability to learn how to learn while students are learning. The main body then provides history and objectives on PBL to provide an initial understanding of PBL learning. The goal of developing students' abilities is to prepare them to deal with real-life situations. Furthermore, the paper uses the cases of the University of Hong Kong and Wuhan Polytechnic as examples of online teaching to analyze how to carry out the practice of online teaching based on the teaching mode of project-based learning (PBL), and then demonstrates benefits in terms of independent ability communication and collaboration ability and reflection competence. Meta-learning skills brought by online education are a treasure for every student. Through autonomous learning, communication and cooperation, and reflection cycle, students can continuously improve and develop. As a consequence of this, both e-learning for helping students comprehending knowledge as well as for enhancing meta-learning skills should not be neglected. We call on students to use online learning effectively and efficiently for lifelong learning. Education provides a steady stream of internal motivation. The application of online PBL teaching methods is becoming more and more extensive. Meanwhile, the need of students' knowledge and society is becoming more and more various. Therefore, the teaching mode also needs to keep pace with the times. The teachers should make the best use of the scheme of online teaching and classroom 
lectures to complete the transfer and integration of online and offline education. They also should learn from the experience of others to improve their own online teaching effect to promote the development of education in our country and cultivate the new type of talent for good.

\section{REFERENCES}

[1]. Wang.N.(2015).Exploration and Practice of PBL Online Teaching Mode Reform of Long-distance and Open Education. Aussie-Sino Studies(4)

[2]. Giannakos, M. N. \& Vlamos, P. (2013). Educational webcasts' acceptance: empirical examination and the role of experience. British Journal of Educational Technology, 44, 1, 125-143.

[3]. Seyoum, Y. (2012). Students perceptions on distance education in Ethiopian higher education: exploring the experience of Haramaya University. International Journal of Online Pedagogy and Course Design, 2, 4, 32-48.

[4]. Tsai, C. W. (2011a). Achieving effective learning effects in the blended course: a combined approach of online self-regulated learning and collaborative learning with initiation. Cyberpsychology, Behavior, and Social Networking, 14, 9, 505-510.

[5]. Tsai, C. W. (2011b). How much can computers and internet help? A long-term study of web-mediated problem-based learning and self-regulated learning. International Journal of Technology and Human Interaction, 7, 1, 67-81.

[6]. Neufeld, V. R., \& Barrows, H. S. (1974). The 'McMaster Philosophy': An approach to medical education. Journal of Medical Education, 49, $1040-1050$

[7]. Albanese, M. A., \& Mitchell, S. (1993). Problembased learning: A review of literature on its outcomes and implementations issues. Academic Medicine, 68, 52-81.

[8]. Baturay, M. H. \& Bay, O. F. (2010). The effects of problem-based learning on the classroom community perceptions. Computers \& Education, $55,1,43-52$.

[9]. Barrows, H. S. (2000). Problem-based learning: Problem-based learning applied to medical education. Springfield, IL: Southern Illinois University School of Medicine.

[10]. Hmelo-Silver, C. E. (2004). Problem-based learning: What and how do students learn? Educational Psychology Review, 16, 235-266.

[11]. Barrow, H. S. (1988). The tutorial process.
Springfield, IL: Southern Illinois University Press.

[12]. Mok, C. K. F., Whitehill, T. L., \& Dodd, B. J. (2008). Problem-based learning, critical thinking and concept mapping in speech-language pathology education: A review. International Journal of Speech-Language Pathology, 10, 438448.

[13]. Hmelo-Silver, C. E., \& Eberbach, C. (2012). Learning theories and problem-based learning. In S. Bridges, C. McGrath, and T. L. Whitehill (Eds.), Problem-based learning in clinical education The next generation (pp. 3-17). New York, NY: Springer.

[14]. Ng, M. L., Bridges, S., Law, S. P., \& Whitehill, T. (2014). Designing, implementing and evaluating an online problem-based learning (PBL) environment-A pilot study. Clinical linguistics \& phonetics, 28(1-2), 117-130.

[15]. Wang.A.(2021). Practice and reflection of online English teaching in higher vocational Colleges based on PBL. Journal of Continuing Higher Education (02),44-47. doi: CNKI:SUN:GDHS.0.2021-02-009. 